Hemisphere that were not observed by any other means. The reasons for these discrepancies are not yet understood.

It has become accepted, as pointed out by S. Self (Arizona State University) and B. Toon (NASA), that sulphur gas content is the important factor determining the longterm climatic effects of eruptions that place material in the stratosphere. Silicate particles are large, fall out rapidly and have only a short-term effect. Sulphur gases, on the other hand, are converted to sulphuric acid particles which are very small and thus have a long mean residence time in the stratosphere - around 2 or 3 years. The particles are very bright and have a large effect on the amount of solar radiation received at the Earth's surface by scattering several per cent of the radiation back to space. It is therefore important to measure the silicate to sulphur ratio of the particles and the concentrations of the sulphur gases that are precursors to the particles, as functions of time and space.

Several NASA research aeroplane flights reached heights of about $20 \mathrm{~km}$ and were able to sample the lower cloud, and samples were also taken of gases currently being emitted by the volcano. Only balloon flights were able to take samples from the main $26 \mathrm{~km}$ cloud. High-altitude aeroplane collections have been examined by scanning electron microscopy and show silicate particles with distinct sulphuric acid pitting. Energy-dispersive X-ray spectrometer analysis of the particles showed sulphur was a significant component. Particles collected by balloon from within the main cloud were at least 95 per cent sulphuric acid. Krueger measured only 3.3 million tons of sulphur dioxide with the TOMS instrument in the eruption cloud on 6 April, but calculations of the total mass based on later observations of the dust particles suggest that more sulphur gas should have been put in by the volcano. Carbon sulphide was not found by the high aeroplanes, but recent samples made at the volcano showed emissions rich in hydrogen sulphide. If the actual eruption cloud had the same composition, then it would take some time for the hydrogen sulphide to convert to sulphur dioxide and then to sulphuric acid particles.

Radiative effects of the dust cloud were seen in ground measurements of incoming solar radiation and optical effects in the sky as well as satellite measurements of the Earth's radiation budget. B. Mendonca (NOAA) and E. Yasukawa (Mauna Loa Solar Observatory) reported that the direct solar radiation at Hawaii was reduced by more than 20 per cent and the total by more than 7 per cent. These are the largest reductions of direct solar radiation ever observed there. J. DeLuisi (NOAA), W. Lockwood (Lowell Observatory) and B. Herman (University of Arizona) all used radiation measurements to estimate the particle size distributions of the cloud. DeLuisi calculated optical depths of the cloud and estimated that its total was about

Immunological diversity

\title{
How the elephant got its trunk
}

\section{from Elizabeth Simpson and Michael Pope}

A PAPER in this issue of Nature (p.388) presents some of the first evidence that gene conversion or homologous recombination may be used to generate a part of the striking polymorphism of transplantation antigens.

Multicellular organisms must distinguish between self and non-self in order to deal with viruses and other harmful foreign invaders. In mammals the immune system has evolved complex defence mechanisms which centre round the activities of B and T lymphocytes. B lymphocytes produce antibodies which bind specifically to foreign determinants (antigens) whereas $T$ lymphocytes recognize antigens only when they are presented together with self, class I or II molecules of the major histocompatibility complex (MHC). Almost all cells of the body have on their surfaces class I MHC molecules; these tissue antigens are also the most important in triggering graft rejection when tissues of one individual are transplanted into a non-identical individual of the same species.

A striking feature of class I MHC molecules is their extraordinary polymorphism - in the mouse there are at least 100 alleles at the principal class I loci. Such polymorphism almost certainly has selective advantage for the species. It has been a matter of speculation, though, as to how this polymorphism arises at the gene level. One hypothesis was that each individual possessed copies of genes for all possible 'alleles' found in the species but that expression was selective. This possibility has been rendered unlikely by the finding that there are too few genes at the principal class I loci ( $H-2 K, D$ and $L$ in the mouse).

\section{5 million tons.}

The radiative effects of the dust cloud and resulting surface air temperature changes were modelled by R. Turco (R\&D Associates), J. Pollack (NASA), F. Luther (Lawrence Livermore National Laboratory) and Robock, each using different types of climate models. All showed cooling, in fair agreement with each other. Robock's model gave timedependent latitude-dependent results, predicting Northern Hemisphere average cooling of about $0.5^{\circ} \mathrm{C}$ during 1984 and 1985 with the effect becoming less after that. Local stratospheric warming of more than $5^{\circ} \mathrm{C}$ has already been observed $(\mathrm{J}$. Angell and R. Quiroz, NOAA; McCormick). It is difficult, however, to separate the signal from the normal quasibiennial temperature variations in the stratosphere that are of about this amplitude. Strong made a controversial
Another possibility is that of gene conversion, by which exons of adjacent homologous genes are recruited into the expressed gene. Analogies exist in bacterial $^{2}$, lower eukaryotic ${ }^{3}$ and viral systems ${ }^{4}$.

Evidence consistent with such a mechanism comes from recent findings of Mellor et al. ${ }^{5}$ who have cloned and sequenced $\mathrm{H}-2 \mathrm{~K}^{\mathrm{b}}$ and mutant $\mathrm{H}-2 \mathrm{~K}^{\mathrm{bm}-1}$ molecules and found fairly extensive DNA sequence alteration in the mutant sequence, suggestive of gene conversion rather than point mutation at the DNA level. The work reported in this issue ${ }^{1}$ shows that isolated partial class I DNA sequences can be inserted and expressed by cellular DNA. DNA clones containing only the first three exons of either a $K^{d}$ or $L^{d}$ gene (the complete gene includes eight exons), were inserted into $L$ cells which then expressed complete $\mathrm{K}^{\mathrm{d}}$ or $\mathrm{L}^{\mathrm{d}}$ molecules on their surfaces, presumably by utilizing their own homologous exons 4-8.

Perhaps class I MHC genes commonly use such gene rearrangements to guarantee their remarkable genetic diversity and possibly this reflects a general strategy by which other polymorphic gene clusters may produce their variability.

Elizabeth Simpson is in the Transplantation Biology Section and Michael Pope in the Clinical Sciences Division of the Clinical Research Centre, Watford Road, Harrow, Middlesex HAI 3 UJ.

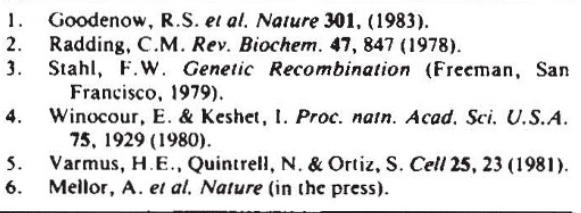

suggestion that the warming was responsible for a weakening of the Hadley cell circulation, resulting in anomalously warm equatorial Pacific sea-surface temperatures and hence affecting the winter climate of North America. His idea is intriguing, but remains to be proved. A model proposed by L. Capone (San José State University) suggested that large anomalies in the stratospheric circulation induced by the warming would explain the high altitude of the cloud as well as its slow spread northwards. El Chichon in Spanish means 'lump on the head', and I am sure the modellers, myself included, will be prepared to accept our chichones should our results prove faulty.

Alan Robock is an Associate Professor in the Department of Meteorology, University of Maryland, College Park, Maryland 20742. 